\title{
Vulnerabilidade e Autonomia na Pesquisa com Adolescentes Privados de Liberdade
}

Vulnerability And Autonomy In The Search With Adolescents Deprived Of Freedom

Vulnerabilidad Y Autonomía En La Investigación Con Adolescentes Privados De Libertad
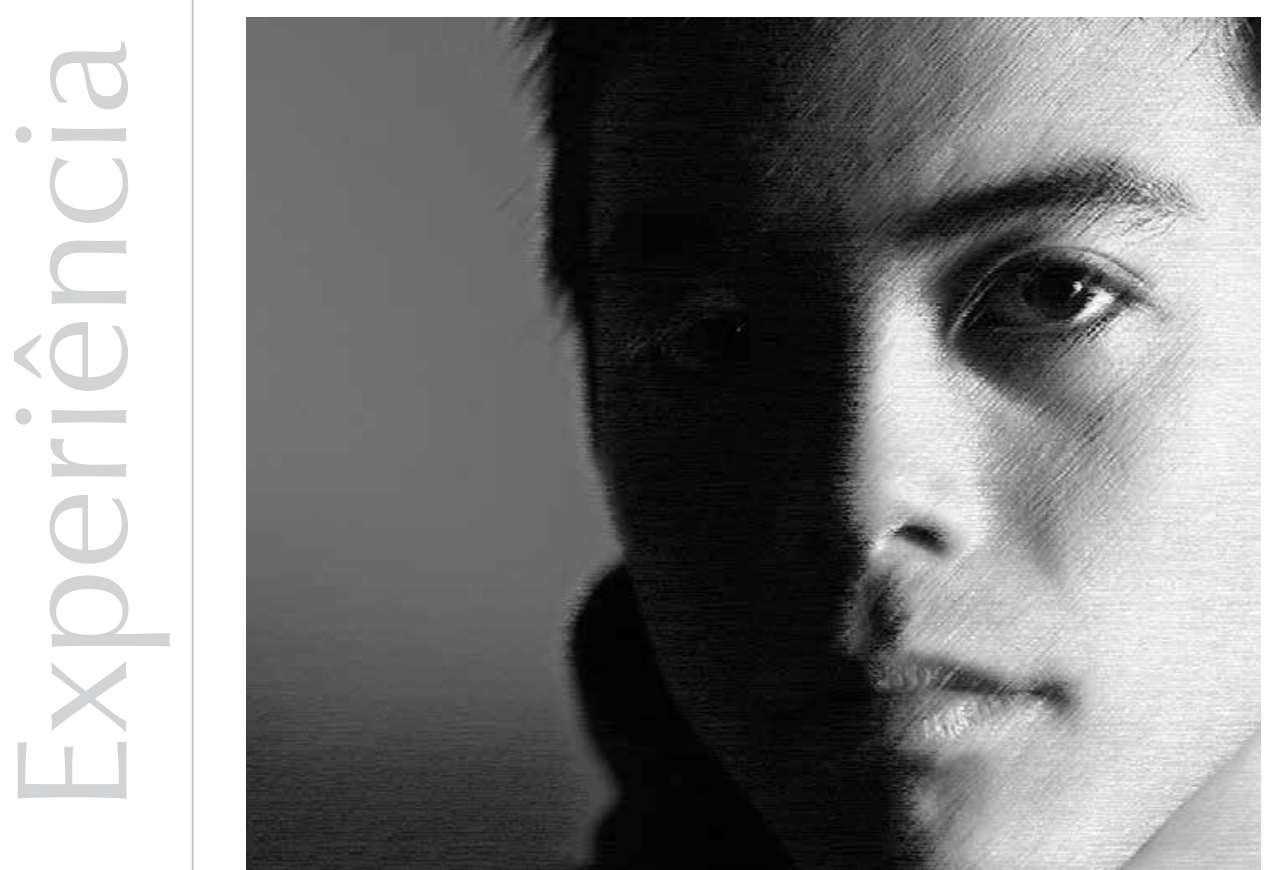
Resumo: O planejamento de pesquisas com adolescentes privados de liberdade deve envolver escolhas éticas e bioéticas com o objetivo de atender a vulnerabilidade desses casos. O maior desafio encontra-se no fato de se buscar garantir o exercício da autonomia e da voluntariedade. Neste trabalho, apresentamos e discutimos as escolhas éticas e bioéticas efetuadas no planejamento de pesquisa que envolve adolescentes privados de liberdade, assim como as medidas especiais adotadas com vistas a garantir a autonomia e a voluntariedade dos participantes. Foram realizadas oficinas prévias que tiveram o objetivo de trabalhar os temas da autonomia e da voluntariedade com todos os adolescentes institucionalizados que tivessem a oportunidade de participar da pesquisa. Com isso, pretendeu-se que os adolescentes se tornassem mais fortalecidos e pudessem utilizar o exercício da autonomia como uma habilidade protetiva. De modo geral, avaliamos que a experiência de realização das oficinas foi bastante enriquecedora tanto para os adolescentes como para as pesquisadoras, e também que as oficinas atingiram os objetivos propostos, de forma que o planejamento resultou bem-sucedido. Os adolescentes iniciaram a participação nas oficinas com uma postura passiva e acrítica, e finalizaram-na com uma postura mais participativa, buscando discutir e esclarecer dúvidas. Sugere-se que essas questões sejam consideradas em estudos com essa população. Palavras-chave:Bioética. Populações Vulneráveis. Psicologia do Adolescente. Adolescente Institucionalizado.

Abstract: The planning of research with adolescents deprived of freedom should consider bioethical and ethical choices aiming at dealing with the vulnerability of these cases. The biggest challenge is the fact that they seek to ensure the exercise of autonomy and willingness. In this paper we present and discuss the ethical and bioethical choices made in the planning of research involving adolescents deprived of freedom, as well as the special procedures adopted to guarantee the autonomy and the willingness of the participants. Previous workshops were held with the aim at dealing with the issues of autonomy and willingness to all institutionalized adolescents who could participate of the research. Thus, the objective was that the adolescents became more empowered and could use the exercise of autonomy as a protective ability. We came to the conclusion that the experience of conducting the workshops was very enriching for both adolescents and for researchers, and also that the workshops were successful, for a successful planning resulted from it. The adolescents started their participation in the workshops with a passive and uncritical attitude, and ended with a more participatory attitude, seeking to discuss and answer the questions. It was suggested that these issues should be considered in studies with this population.

Keywords: Bioethics. Vulnerable Populations. Adolescent Psychology. Adolescent Institutionalized.

Resumen: La planificación de investigación con adolescentes privados de libertad debe involucrar elecciones éticas y bioéticas con el objetivo de atender la vulnerabilidad de esos casos. El mayor desafío se encuentra en el hecho de buscar garantizar el ejercicio de la autonomía y de la voluntariedad. En este trabajo, presentamos y discutimos las elecciones éticas y bioéticas efectuadas en la planificación de investigación que involucra adolescentes privados de libertad, así como las medidas especiales adoptadas con vistas a garantizar la autonomía y la voluntariedad de los participantes. Fueron realizados talleres previos que tuvieron el objetivo de trabajar los temas de la autonomía y de la voluntariedad con todos los adolescentes institucionalizados que tuviesen la oportunidad de participar de la investigación. Con eso, se buscó que los adolescentes se fortalecieran más y pudiesen utilizar el ejercicio de la autonomía como una habilidad protectiva. De modo general, evaluamos que la experiencia de realización de los talleres fue bastante enriquecedora tanto para los adolescentes como para las investigadoras, y también que las oficinas alcanzaron los objetivos propuestos, de forma que la planificación resultó exitosa. Los adolescentes iniciaron la participación en los talleres con una postura pasiva y acrítica, y la finalizaron con una postura más participativa, buscando discutir y aclarar dudas. Se sugiere que esas cuestiones sean consideradas en estudios con esa población.

Palabras clave: Bioética. Poblaciones Vulnerables. Psicología del Adolescente. Adolescente Institucionalizado.

A violência tem sido um tema bastante abordado na atualidade, e ocupa espaço tanto na mídia quanto na produção científica. Trata-se de um problema de saúde pública, que gera consequências diretas e indiretas tanto para as vítimas quanto para os agressores (Brasil, 2005a). Um aspecto particularmente preocupante dessa questão refere-se à associação entre violência e juventude, pois, entre os jovens, encontramos as mais altas estatísticas de mortalidade por causas externas, assim como são os jovens os mais apontados como autores de agressões, tanto no País quanto na América Latina (Krug, 2002). Nesse sentido, a criminalidade em adolescentes em conflito com a lei e em 
situação de risco foi incluída na agenda nacional de prioridades de pesquisa em saúde (Brasil, 2005b). Nossa investigação contempla essa agenda de prioridades, sendo nossa questão específica de estudo problematizar os processos de identificação que levam adolescentes a praticar atos infracionais.

Entende-se que a realização de pesquisas com adolescentes em conflito com a lei exige um planejamento especial, principalmente do ponto de vista bioético, dadas as particularidades dessa população, sobretudo quando se encontra institucionalizada para cumprimento de medida socioeducativa, cuja aplicação é destinada a adolescentes autores de atos infracionais (Brasil, 1990).

O Estatuto da Criança e do Adolescente (ECA) prevê tanto medidas socioeducativas em meio aberto (advertência, obrigação de reparar o dano, prestação de serviços à comunidade e liberdade assistida) quanto medidas restritivas (inserção em regime de semiliberdade) e privativas de liberdade (internação em estabelecimento educacional). Através de tais medidas, o adolescente é responsabilizado pelos seus atos, considerando-se a sua condição peculiar de pessoa em desenvolvimento, sendo que, na sua aplicação, deve ser considerada a capacidade do jovem em cumpri-la, as circunstâncias e a gravidade da infração cometida. A medida de internação é considerada último recurso, e aplicada a situações de extrema gravidade, em que não há outra medida mais adequada, sendo sujeita aos princípios de brevidade e de excepcionalidade (Brasil, 1990). Embora haja a indicação de priorizar as medidas em meio aberto, pois em geral são mais bem-sucedidas e acarretam menos danos à vida dos jovens, sabe-se que vários fatores contribuem para que a internação seja uma medida ainda muito utilizada. Entre eles, destacam-se as fragilidades dos programas de execução de medidas em meio aberto ou mesmo a inexistência destes em alguns Municípios, e ainda a permanência de um imaginário social que valoriza o castigo e a punição, exigindo penas severas (Brasil, 2006).

Diante disso, compreende-se como a internação de jovens ainda tem sido um recurso bastante utilizado para cumprimento de medida socioeducativa. A atuação do psicólogo está prevista na execução da medida socioeducativa, o que coloca para esse profissional uma série de problematizações, dado que exige uma atuação diferenciada daquela considerada clássica ou típica: a prática em consultório. A atuação do psicólogo em um contexto institucional se configura como uma situação que exige um manejo técnico específico, que se diferencia das técnicas de trabalho mais tradicionais. Guirado (2006), por exemplo, discute o exercício da técnica psicanalítica em uma instituição que atende adolescentes em cumprimento de medidas socioeducativas e indica a necessidade de se repensar a clínica psicanalítica quando ela é exercida em um contexto institucional. Nesse sentido, a autora defende a necessidade de ajustes tanto na técnica quanto na própria teoria, discutindo principalmente os conceitos de transferência e de contexto institucional. Em suma, discutese a necessidade de se considerar que a transferência contada como fundamental é aquela feita com a instituição, e não com o profissional que realiza o atendimento, o que é determinante dos sentidos que se constroem para a relação terapêutica.

Considerando-se que a internação independe da vontade do adolescente, pois é determinada judicialmente, e ainda 
A adolescência tem sido descrita como um processo psíquico caracterizado pela busca de autonomia e de reconhecimento social, sendo assim um momento de passagem caracterizado por intensa insegurança (Calligaris, 2000). a existência de práticas coercitivas e estigmatizantes nesses estabelecimentos (Conselho Federal de Psicologia, 2006; Oliveira \& Assis, 1999), pode-se imaginar que a transferência para a instituição comporta alguns (ou muitos!) elementos negativos, e isso vai inevitavelmente comprometer o estabelecimento de um vínculo terapêutico. Diante disso, coloca-se para o profissional psicólogo um grande desafio no sentido do manejo relativo à transferência institucional.

Nossa experiência de realização de uma pesquisa com jovens institucionalizados para cumprimento de medida socioeducativa, principalmente os procedimentos prévios à coleta de dados, possibilitou a discussão e a busca de alternativas para o enfrentamento dessas questões, o que foi a principal motivação para elaborar este trabalho. Ao relatarmos essa experiência de pesquisa, esperamos fornecer elementos que possam ser úteis para uma discussão sobre o trabalho com adolescentes institucionalizados.

\section{A vulnerabilidade de jovens privados de liberdade: desafio à garantia da voluntariedade $\mathrm{e}$ da autonomia}

Ao mesmo tempo em que os adolescentes institucionalizados para cumprimento de medida socioeducativa constituem um público-alvo para a pesquisa sobre violência e criminalidade na adolescência, considerada uma prioridade (Brasil, 2005b), eles podem ser considerados vulneráveis, o que deve ser considerado no planejamento da pesquisa. Em função disso, devem ser adotados procedimentos de pesquisa específicos que considerem as peculiaridades desses casos.

Os principais aspectos promotores de vulnerabilidade desses possíveis participantes são a própria condição de desenvolvimento psíquico em que se encontram (adolescência), o contexto social em que estão inseridos e a institucionalização. Segundo Diniz e Correa (2001), o conceito de vulnerabilidade foi incorporado aos debates bioéticos apenas a partir da década de 90, considerando-se vulnerável toda pessoa que se encontra menos apta a se proteger.

Primeiramente, o adolescente pode ser considerado vulnerável em função de sua condição de desenvolvimento incompleto, que não the garante o pleno exercício da autonomia. Dolto (1991) utiliza a expressão "complexo da lagosta" para se referir ao processo da adolescência, afirmando que, tal como a lagosta, o adolescente perde sua "carapaça" (condição de dependência infantil) para alcançar outra (condição de independência adulta), e, durante esse processo, encontra-se temporariamente desprotegido. A adolescência tem sido descrita como um processo psíquico caracterizado pela busca de autonomia e de reconhecimento social, sendo assim um momento de passagem caracterizado por intensa insegurança (Calligaris, 2000).

Outro aspecto entendido como promotor de vulnerabilidade é o contexto social no qual estão inseridos os adolescentes em conflito com a lei. Vários estudos revelam que esses jovens, em sua maioria, são oriundos de classes populares, contexto que, por sua vez, se associa a opressão e a pobreza (Diniz \& Correa, 2001; Volpi, 1997). Em decorrência disso, os conceitos de vulnerabilidade e de desigualdade se aproximam, pois não são vulneráveis apenas aquelas categorias historicamente consideradas como tal, ou seja, os deficientes mentais, físicos, as crianças, os senis e os institucionalizados. Também devem ser consideradas vulneráveis 
todas as pessoas que se encontram em situação de vulnerabilidade social, como ocorre, por exemplo, com as populações subdesenvolvidas, ou em situação de risco psicossocial, como é o caso dos adolescentes em conflito com a lei (Diniz \& Correa, 2001).

Finalmente, a institucionalização é reconhecidamente promotora de vulnerabilidade ao distribuir desigualmente o poder entre os que o detém e os que se submetem a ele. Assim, a vulnerabilidade se associa com o estabelecimento de relações assimétricas, que precisam ser avaliadas para que possam ser conhecidas. A partir disso, deve-se buscar minimizar a fragilidade dos sujeitos como forma de protegê-los (Guilhem, Oliveira, \& Carneiro, 2005). No caso específico das instituições socioeducativas brasileiras, há que se considerar, ainda, a existência de práticas coercitivas, discriminatórias e violadoras de direitos, que acabam agravando essa situação. São amplamente conhecidas as dificuldades históricas ainda encontradas nesses estabelecimentos, como superlotação, irregularidades na oferta de ensino regular, presença de maus-tratos, etc., o que intensifica a desigualdade na distribuição do poder (Conselho Federal de Psicologia, 2006; Oliveira \& Assis, 1999).

Nesse sentido, o planejamento de uma pesquisa com esse público deve envolver escolhas éticas e bioéticas para tentar lidar com as especificidades desses casos. Dentre essas escolhas, consideramos que o maior desafio se encontra no fato de se buscar garantir o exercício da autonomia e da voluntariedade, comprometido pela vulnerabilidade encontrada nesses casos. Em função disso, torna-se necessário adotar procedimentos especiais para proteger os participantes da pesquisa. Neste trabalho, apresentamos e discutimos as escolhas éticas e bioéticas que foram planejadas visando a dar conta das especificidades dos casos de adolescentes em conflito com a lei privados de liberdade, o que constituiu uma experiência prévia à realização da pesquisa propriamente dita. Os resultados obtidos através dessa experiência foram tão significativos quanto os que foram obtidos através da pesquisa realizada posteriormente, de modo que consideramos bastante pertinente divulgar essa experiência, que poderá ser útil para pesquisadores e profissionais com interesse nesse público.

Os procedimentos éticos e bioéticos foram planejados com base nas Resoluções no 196/96, do Conselho Nacional de Saúde, e no 016/2000, do Conselho Federal de Psicologia, e baseiam-se no modelo principialista proposto por Beauchamp e Childress (1979). Esses princípios visam a garantir a dignidade dos sujeitos que participam de pesquisas, que devem ser respeitados em sua autonomia e defendidos em sua vulnerabilidade. A beneficência implica a necessidade de ponderar entre riscos e benefícios, tanto atuais como potenciais, individuais ou coletivos, comprometendo-se com o máximo de benefícios e o mínimo de danos e riscos. Os danos previsíveis deverão ser evitados, seguindo-se o princípio da não maleficência. Os princípios de justiça e de equidade indicam a necessidade de relevância social da pesquisa, com vantagens significativas para os sujeitos da pesquisa e minimização do ônus para os sujeitos vulneráveis, garantindo-se igual consideração dos interesses envolvidos e da destinação socio-humanitária. Desses princípios, o da autonomia é reconhecido pelos bioeticistas como o mais importante, mas também como o mais problemático (Polli, 2006). Ele se encontra em jogo especialmente nas situações nas quais os participantes da pesquisa estão submetidos a condições de 
vulnerabilidade, quando será necessário adotar medidas especiais que proporcionem amparo e/ou proteção.

Assim, entendemos que seria necessário oferecer especial atenção ao princípio de autonomia, manifestado pela necessidade do consentimento voluntário, que significa garantir ao sujeito pesquisado o livre direito de escolha sem qualquer intervenção de elementos de força, fraude, mentira, coação, astúcia ou outra forma de restrição posterior, além de garantir que o conhecimento que possui do assunto em estudo deve ser suficiente para tomar uma decisão (Guilhem, Oliveira, \& Carneiro, 2005). No caso dos adolescentes institucionalizados para cumprimento de medida socioeducativa, público-alvo da pesquisa, essas questões mostram-se mais delicadas. Como garantir que se sintam livres em um contexto em que suas liberdades estão efetivamente restringidas, onde muitas vezes seus direitos também são violados? Como desvincular a pesquisa da institucionalização, já que ela será conduzida no ambiente institucional? Como desvincular a pesquisa da institucionalização, já que a autora da pesquisa é também psicóloga da instituição onde será realizada a pesquisa? Tais questionamentos exigiram do grupo de pesquisadores uma série de discussões e de planejamentos visando a solucionar essas dificuldades.

A assinatura formal do Termo de Consentimento Livre Esclarecido (TCLE), documento que expressa o consentimento voluntário, faz parte desse processo, mas não é garantia absoluta. Diniz e Correa denunciam que, apesar da declaração da essencialidade do consentimento voluntário dos participantes que colaboram com as pesquisas, já foram conduzidos experimentos perversos e abusivos que envolviam comunidades vulneráveis, tais como pessoas institucionalizadas, indicando que essa questão não se resolve com a mera assinatura do TCLE. Em função do alto grau de coerção a que são cotidianamente expostos esses adolescentes no contexto institucional, a assinatura formal de um TCLE não pode ser tomada, unicamente, como garantia do exercício da voluntariedade.

Neiva-silva, Lisboa e Koller (2005), discutindo os problemas bioéticos na pesquisa com crianças e adolescentes em situação de risco, defendem a necessidade de que o TCLE deixe de ser apenas um registro concreto de uma autorização legal, passando a ser concebido como um processo comunicativo que precede a decisão autônoma de participar de um tratamento de saúde ou de pesquisa. Com relação a isso, Vieira (2005) sustenta que, além de se garantir a voluntariedade, é preciso entender as razões que levam uma pessoa a se apresentar como voluntária para uma pesquisa, explicitando-as ao máximo. Além disso, segundo a autora, é preciso questionar se as pessoas que assinam um TCLE realmente entenderam a proposta ali contida. Quanto à pesquisa com sujeitos privados de liberdade, a autora afirma que, em tese, prisioneiros são pessoas competentes para decidir se querem ou não participar de uma pesquisa, mas, na prática, são pessoas vulneráveis e sujeitas ao abuso.

Ainda que a elaboração do TCLE seja um passo importante, é fundamental discutir o processo da sua obtenção, "buscando impedir o estabelecimento de uma relação assimétrica entre pesquisador e sujeito, o que poderia resultar em formas camufladas de opressão e coerção" (Guilhem, Oliveira, \& Carneiro, 2005, p. 122). Assim, o debate ético frente à vulnerabilidade deverá privilegiar o desenvolvimento de habilidades 
e de capacidades que tornem as pessoas realmente livres para decidir sobre o que é melhor para as suas vidas, o que é possível através do desenvolvimento de uma "postura crítica que lhes permitirá o enfrentamento e a contraposição a pesquisadores, experimentos e ao poder que os recoloca em situação de desrespeito e injustiça" (Guilhem, Oliveira, \& Carneiro, 2005, p. 122).

A pertinência do modelo principialista tornase discutível quando aplicado à pesquisa que envolve seres humanos em nossas sociedades complexas e diferenciadas, onde se verifica uma contestação permanente dos paradigmas científicos e éticos. Nesse contexto, torna-se necessário considerar, também, o princípio de proteção como um princípio ético aplicável às situações de carência, quando não estão garantidas as condições de um consentimento livre e esclarecido efetivo (Schramm, Palácios, \& Rego, 2008).

Diante dessas questões, fomos levados a conceber a obtenção do consentimento livre esclarecido como um processo, e não apenas como uma formalidade, planejado com vistas a proteger os sujeitos da pesquisa em função das condições de vulnerabilidade em que se encontram, momento em que as questões expostas até aqui poderão ser trabalhadas.

O presente trabalho teve como objetivos: a) apresentar e discutir as escolhas éticas e bioéticas efetuadas no planejamento de pesquisa que envolve adolescentes privados de liberdade e b) apresentar e discutir as medidas especiais adotadas com vistas a garantir a autonomia e a voluntariedade dos participantes da pesquisa, que são considerados vulneráveis.

\section{A proposta de trabalho com oficinas}

Atendendo a algumas sugestões propostas pelos autores que apresentamos acima, a explicitação das condições de vulnerabilidade desses participantes foi tida como um primeiro passo no processo de realização da pesquisa. A partir disso, foi planejada a realização de oficinas prévias nas quais se pretendeu trabalhar os temas de autonomia e voluntariedade com todos os adolescentes institucionalizados que preenchiam os critérios de participação na pesquisa. O objetivo dessas oficinas foi oferecer subsídios para a discussão e o entendimento dos princípios bioéticos, enfatizando-se o caráter de autonomia e de participação voluntária em pesquisas. Com isso, pretendeu-se que os adolescentes se tornassem mais fortalecidos e pudessem utilizar o exercício da autonomia como uma habilidade protetiva.

Foram convidados para participar das oficinas 10 adolescentes do sexo masculino internados para cumprimento de medida socioeducativa em uma unidade regional situada no Rio Grande do Sul. A unidade possui capacidade para atender 40 adolescentes, e, no momento da realização das oficinas, estava com uma população um pouco acima da sua capacidade. Os participantes foram escolhidos através dos seguintes critérios de inclusão: a) estar iniciando ou cumprindo medida socioeducativa de internação pela primeira vez, b) ser natural e procedente do Município onde a unidade está localizada e c) aceitar voluntariamente participar da pesquisa. Os dois primeiros critérios foram estabelecidos em função de nosso interesse de realizar um estudo longitudinal, situando o primeiro encontro com o adolescente no momento em que este inicia o cumprimento da medida socioeducativa pela primeira vez, 
pois, na unidade, existem adolescentes com diversas internações. O segundo critério, especificamente, foi estabelecido em função de viabilizar a continuidade do estudo em outros momentos sem a necessidade de realização de viagens, pois, como a unidade é regional, recebe também adolescentes de outros Municípios.

Dois adolescentes recusaram o convite para participar das oficinas e um estava em horário de aula, dessa forma, participaram do trabalho sete adolescentes e três pesquisadoras. A recusa desses dois adolescentes foi importante para apontar e discutir a necessidade de voluntariedade na participação tanto das oficinas quanto da própria pesquisa.

Nessas oficinas, os objetivos da pesquisa foram apresentados igualmente a todos os adolescentes, oferecendo-lhes a possibilidade de participação voluntária na pesquisa. Tendo em vista que a autora da pesquisa é integrante do quadro funcional da instituição, um procedimento especial adotado foi a inserção de uma outra profissional, também psicóloga, na realização da pesquisa, que não possui vínculo com a instituição e que ficou responsável pela realização das oficinas, pelo processo de obtenção e assinatura do TCLE e pela coleta dos dados através de entrevistas guiadas. Esse procedimento visou a minimizar a desigualdade de poder entre pesquisador e pesquisados na situação de institucionalização.

\section{Refletindo sobre as oficinas}

As oficinas foram planejadas para ocorrer em dois momentos: no primeiro, houve a apresentação das pesquisadoras e a discussão dos princípios bioéticos que devem ser observados em pesquisas com seres humanos. Nossa proposta incluiu um relato histórico dessas questões, apresentando casos reais em que houve desrespeito aos participantes de pesquisas, como aquelas que foram conduzidas durante a $2^{\underline{a}}$ Guerra Mundial (Vieira, 2005). No segundo encontro, apresentaram-se os objetivos da pesquisa que pretendíamos realizar e as informações constantes no TCLE. Este foi elaborado em uma linguagem acessível, buscando facilitar o entendimento do adolescente, e continha as seguintes informações: breve apresentação do tema, dos objetivos, da justificativa e da metodologia da pesquisa ("Estamos realizando uma pesquisa que busca estudar o caso de adolescentes em conflito com a lei que cumprem medida socioeducativa de internação, com o objetivo de entender como o adolescente chega a envolverse com a violência e a prática de atos infracionais. Além disso, estamos interessados em conhecer como esses jovens se percebem e percebem outros jovens que cumprem medida socioeducativa. Consideramos que esse conhecimento será útil para podermos auxiliar adolescentes que praticam atos infracionais. Para isso, pretendemos conversar com você, através de uma entrevista, para vermos como você está percebendo a sua internação, você mesmo e seus projetos futuros"), garantias quanto à preservação da identidade, do sigilo e da confidencialidade dos dados, além dos riscos e benefícios previstos ("A sua identidade será preservada, e sua participação não irá interferir no cumprimento da medida socioeducativa. Você é inteiramente livre para aceitar participar deste estudo, e poderá encerrar sua participação a qualquer momento, inclusive se sentir desconforto e desejar não responder a alguma questão formulada. A sua participação não acarreta riscos físicos para você, uma vez que não são adotados procedimentos invasivos. Garantimos o anonimato e a confidencialidade das 
informações prestadas. Da mesma forma, não estão previstos benefícios diretos aos que decidirem participar. Contudo, quem estiver participando do estudo estará auxiliando a compreender como jovens que cumprem medida socioeducativa se envolvem em atos infracionais e o que eles planejam para seu futuro"), e informações sobre a divulgação dos resultados, do grupo de pesquisadores e do Comitê de Ética ao qual o projeto foi submetido ("Os resultados serão repassados à instituição, em forma de relatório de pesquisa, assim que o trabalho estiver concluído, contudo, o anonimato dos participantes será preservado"). No final dos encontros, procurou-se fazer que os adolescentes expressassem o que haviam aprendido com o trabalho através de desenhos.

No primeiro encontro, logo após a apresentação das pesquisadoras e do objetivo das oficinas, os adolescentes verbalizaram que gostariam de participar da pesquisa e que não precisavam de nenhuma outra informação. Explicamos então que era necessário informá-los dos procedimentos do estudo, especialmente dos riscos e dos benefícios previstos. Os jovens então escutaram atentamente as informações, e mostraram-se especialmente interessados pelos dados históricos e pelas situações concretas apresentadas, revelando que esses aspectos eram desconhecidos por eles até então. Ao final desse encontro, foi solicitado aos jovens que expressassem graficamente o que haviam compreendido do exposto. Nesse momento, três adolescentes saíram da sala, alegando que já estavam esclarecidos sobre a pesquisa e que gostariam de aproveitar o horário para ir ao pátio tomar sol, o que não seria possível mais tarde em função das rotinas da unidade. Como nosso interesse era não prejudicá-los, garantiu-se que eles não eram obrigados a participar, podendo sair das oficinas, aproveitando-se mais uma vez a ocasião para explicitar a voluntariedade e o princípio da não maleficência. Esses jovens sugeriram que o próximo encontro ocorresse no pátio, para que não precisassem optar entre tomar sol ou participar das oficinas.

Diante disso, consideramos que esses adolescentes expressaram em ato como haviam assimilado os princípios da autonomia, da voluntariedade e da não maleficiência, recémtrabalhados na oficina, além de buscarem uma confirmação prática de que nossa ação corresponderia ao discurso apresentado. Permaneceram na sala quatro adolescentes que fizeram desenhos, porém nenhum deles parecia diretamente relacionado com os conteúdos trabalhados nas oficinas. Além disso, demonstraram dificuldade para falar sobre os desenhos. Os jovens pareceram inibidos pela presença dos outros adolescentes e das pesquisadoras, que não Ihes eram familiares. O único adolescente que falou sobre o desenho que fez foi o que desenhou uma flor, e disse que ela representava cuidado, conteúdo que efetivamente foi trabalhado durante a oficina. Mais adiante, com o desenvolvimento da pesquisa e a realização de entrevistas, foi possível identificar que seus desenhos estavam relacionados com questões subjetivas, e já atendiam indiretamente aos objetivos propostos no estudo. Nesse sentido, talvez seja possível tomá-los como uma expressão indireta dos conteúdos trabalhados nas oficinas: já que estávamos interessadas em conhecê-los, eles já mostraram um pouco de si mesmos através dos desenhos, ainda que indiretamente.

O segundo encontro foi dividido em dois momentos, para que não houvesse coincidência entre o tempo a ser passado no pátio e a realização da oficina. Nesse encontro, 
os adolescentes mostraram-se mais engajados e participaram ativamente das discussões, mostrando-se mais familiarizados com as pesquisadoras e com o grupo, e questionaram especialmente sobre o sigilo e os objetivos da pesquisa, demonstrando preocupação quanto ao destino de seus depoimentos. Os jovens indagaram principalmente se o Juizado teria acesso aos dados, e se isso teria alguma influência em suas situações processuais, e foram esclarecidos que isso não ocorreria de modo algum. Apesar de oferecermos todas as garantias relativas ao sigilo e à confidencialidade dos dados, um adolescente optou por não participar da pesquisa afirmando que, "com essas questões de Justiça, não se deve brincar, principalmente quem responde a processos ainda não concluídos". É importante ressaltar que, no início do primeiro encontro, esse adolescente, assim como os demais, já havia manifestado concordância em participar da pesquisa. Assim, sua recusa pode significar que a participação nas oficinas tenha possibilitado que exercesse crítica sobre sua escolha inicial, o que consideramos um resultado positivo do ponto de vista dos objetivos das oficinas.

Quanto aos objetivos da pesquisa, indagaram sobre nossa motivação: por que o interesse neles? Justificamos nosso interesse afirmando que suas vivências podem ser representativas das vivências de outros adolescentes em conflito com a lei, cuja compreensão pode contribuir para a qualificação das políticas de atendimento. Nesse momento, um adolescente afirmou que, para sabermos de sua vida, bastava ouvir o rap Depoimento de um Viciado, que ele passou a cantar e no qual foi acompanhado pelos demais adolescentes. Após cantar, afirmou: "é, isso deve ser a realidade de vários adolescentes como eu", o que foi confirmado pelos demais. Com isso, foi possível perceber que a letra do rap trazida para o grupo expressava conteúdos relacionados ao contexto de vida desses adolescentes, e nesse caso específico, o rap expressava principalmente conteúdos relacionados com a drogadição. O uso de drogas é um aspecto do problema do adolescente em conflito com a lei, pois vários estudos indicam que há uma forte associação entre o uso de drogas e a prática de atos infracionais (Heim \& Andrade, 2007; Martins \& Pillon, 2008; Sena \& Colares, 2008). Além disso, a utilização do rap revela um modo de expressão que remete à constituição de grupos, dimensão importante no desenvolvimento do adolescente. Desse modo, o rap pôde ser visto como uma forma de narrativa rica em conteúdo, utilizado como veículo de comunicação. Supomos, ainda, que o rap possa ser revelador dos processos de identificação e de construção de si mesmo, sendo utilizado pelos adolescentes como forma de expressão de como percebem a si mesmos, ao outro e ao contexto no qual estão inseridos. Assim, consideramos esse momento da realização da oficina como uma nova confirmação indireta de que os adolescentes entenderam os objetivos da pesquisa conforme apresentamos, e que estavam dispostos a colaborar.

Esse adolescente que propôs ouvirmos o rap havia afirmado que não estava bem quando chegou à oficina, e tinha permanecido calado até esse momento. Após cantar, sorriu e mostrou-se mais descontraído, o que utilizamos para ilustrar o princípio da beneficiência, visto que a participação na oficina fez que ele se sentisse melhor, ou mesmo se sentisse compreendido em sua forma de expressão.

Ao final das oficinas, seis adolescentes aceitaram o convite para participar da pesquisa e assinaram o TCLE. 


\section{Considerações finais}

A vulnerabilidade característica dos casos de adolescentes privados de liberdade pode ser considerada uma dificuldade ao atendimento das exigências éticas e bioéticas de pesquisas com seres humanos, principalmente com relação ao exercício da autonomia e da voluntariedade. A vulnerabilidade identificada nesses casos está associada com a própria adolescência, com o contexto social no qual esses adolescentes estão inseridos e com a institucionalização. Em nosso trabalho, tomamos essa dificuldade como um desafio e fomos em busca de estratégias que visassem a minimizar tal dificuldade. A experiência realizada constituiu um dos momentos mais ricos da realização da pesquisa, de modo que consideramos absolutamente pertinente divulgá-la. A partir disso, pretende-se sensibilizar outros pesquisadores para essas questões, ampliando assim as possibilidades de proteção desses adolescentes quando participam de pesquisas. Além disso, entende-se que o tema pode ser útil também no sentido da atuação profissional do psicólogo junto a esse público.

De modo geral, avaliamos que a discussão acerca dos obstáculos para a obtenção do Consentimento Livre e Esclarecido de adolescentes em conflito com a lei privados de liberdade foi muito pertinente e absolutamente necessária, tendo em vista a vulnerabilidade desses participantes. A experiência de realização das oficinas foi bastante enriquecedora tanto para os adolescentes como para as pesquisadoras, e assim acreditamos que as oficinas tenham atingido os objetivos propostos.

Nas oficinas, os adolescentes tiveram inicialmente uma postura passiva e acrítica, e no final passaram a ter uma postura mais participativa, buscando discutir e esclarecer dúvidas. Assim, concluímos que o conhecimento inicial que possuíam sobre o assunto realmente não era suficiente para exercer crítica e tomar uma decisão, o que foi desenvolvido através da realização das oficinas, onde receberam algumas informações e foram incentivados a exercer a autonomia e a voluntariedade.

Além disso, os adolescentes expressaram de modo peculiar o que aprenderam a respeito dos princípios bioéticos trabalhados, e suas formas de expressão acabaram revelando também um pouco de si mesmos, visto que tenderam a utilizar mais o ato que a palavra como recurso de expressão. O rap trazido pelos próprios adolescentes durante as oficinas também se mostrou um recurso expressivo importante que pode ser utilizado em atividades práticas realizadas com eles, tanto em termos de pesquisas quanto de intervenções profissionais.

Salienta-se a pertinência da proposta de se considerar a assinatura do TCLE um processo, e não apenas uma formalidade (Neivasilva, Lisboa, \& Koller, 2005). Graças a essa consideração, planejamos a realização das oficinas e, a partir disso, foi possível estabelecer uma relação comunicativa satisfatória entre adolescentes e pesquisadoras. Avaliamos que os adolescentes entenderam nossos objetivos, assim como foram entendidos em suas formas de expressão peculiares.

Sugere-se que esses assuntos sejam considerados em estudos com essa população que, dada sua vulnerabilidade, costuma ser bastante solícita em participar de pesquisas, mas que certamente não possui condições prévias de avaliar criticamente essa participação, de exercer autonomia e de 
garantir a voluntariedade, protegendo-se de situações abusivas. A legislação pertinente a esses casos enfatiza a necessidade de oferecer proteção integral a crianças e a adolescentes (Brasil, 1990), o que acarreta uma série de deveres aos responsáveis por isso: a família, o Estado, a sociedade. Tal ordenamento deve repercutir em toda forma de contato com esse público, de modo que, na realização de uma pesquisa, cabe ao pesquisador o dever de garantir a proteção dos sujeitos da pesquisa quando estes forem crianças ou adolescentes. De um ponto de vista mais amplo, acreditamos que a experiência relatada possa ser útil também para pensarmos sobre o planejamento de intervenções do profissional psicólogo no contexto do atendimento institucional ao adolescente em conflito com a lei. Considerando-se os obstáculos que se colocam para a construção da relação terapêutica no contexto institucional, acreditamos que a explicitação desses obstáculos deva ser tomada como um primeiro passo no sentido de enfrentar essas questões. A seguir, compreende-se que é necessário buscar o estabelecimento de uma relação comunicativa satisfatória, considerando-se as peculiaridades desses casos, o que vai possibilitar discuti-los e problematizá-los, visando à proteção e ao desenvolvimento de habilidades tanto no profissional quanto nos adolescentes que tenham como objetivo o enfrentamento dos obstáculos que se colocam. Acreditamos que essa atuação poderá ser tão enriquecedora quanto consideramos que tenha sido a experiência que relatamos neste trabalho. 
Jana Gonçalves Zappe

Doutoranda em Psicologia pela Universidade Federal do Rio Grande do Sul, Porto Alegre - RS - Brasil.

E-mail: janazappe@hotmail.com

\section{Cristiane Rosa dos Santos}

Mestranda em Psicologia pela Universidade Federal de Santa Maria, Santa Maria - RS - Brasil.

E-mail: cristianerosapsi@hotmail.com

\section{lara da Silva Ferrão}

Psicóloga formada pela Faculdade Integrada de Santa Maria, Santa Maria - RS - Brasil.

E-mail: iaraferrao@hotmail.com

\section{Ana Cristina Garcia Dias}

Doutora em Psicologia pela Universidade de São Paulo e professora adjunta da Universidade Federal de Santa Maria, Santa Maria - RS - Brasil.

E-mail: anacristinagarciadias@gmail.com

Endereço para envio de correspondência:

Estrada Padre Gabriel Bolzan, n. 40, Cerrito. CEP: 97095-500. Santa Maria, RS

Recebido: 16/02/2011, 1a Reformulação: 10/08/2012 Aprovado: 29/11/2012. 
Beauchamp, T., \& Childress, J. (1979). Principles of biomedical ethics. New York: Oxford University Press.

Brasil. Ministério da Justiça. (1990). Estatuto da Criança e do Adolescente. Brasília, DF.

Brasil. Ministério da Saúde \& Conselho Nacional de Saúde. (1996). Normas de pesquisa envolvendo seres humanos. Res. CNS 196/96.

Brasil. Ministério da Saúde. (2005a). Impacto da violência na saúde dos brasileiros. Brasília, DF: Ministério da Saúde.

Brasil. Ministério da Saúde. (2005b). Agenda nacional de prioridades de pesquisa em saúde. Brasília, DF: Editora do Ministério da Saúde.

Brasil. Secretaria Especial dos Direitos Humanos. (2006). Sistema Nacional de Atendimento Sócio-Educativo - SINASE. Brasília, DF: Conanda.

Calligaris, C. (2000). Adolescência. São Paulo: Publifolha. Conselho Federal de Psicologia. (2000). Resolução no 16/00 - Realização de Pesquisa em Psicologia com Seres Humanos. Brasília, DF

Conselho Federal de Psicologia (2006). Direitos humanos: um retrato das unidades de internação de adolescentes em conflito com a lei. Brasília, DF: Autor.

Conselho Nacional da Saúde. (1996, 10 out.). Resolução $n^{\circ}$ 196/96 - Diretrizes e Normas Regulamentadoras de Pesquisas Envolvendo Seres Humanos. Brasília, DF.

Diniz, D., \& Correa, M. (2001). Declaração de Helsinki: relativismo e vulnerabilidade. Cadernos de Saúde Pública, 17(3), 679-688.

Dolto, F. (1991). Palavras para adolescentes ou o complexo da lagosta. Venda Nova: Bertrand Editora.

Guilhem, D., Oliveira, M., \& Carneiro, M. (2005). Bioética, pesquisa envolvendo seres humanos. Revista Brasileira Ciência e Movimento, 13(1), 117-123.
Guirado, M. (2006). A psicanálise dentro dos muros de instituições para jovens em conflito com a lei. Boletim de Psicologia, 55(124), 53-66.

Heim, J., \& Andrade, A. G. (2007). Efeitos do uso do álcool e das drogas ilícitas no comportamento de adolescentes de risco: uma revisão das publicações científicas entre 1997 e 2007. Revista de Psiquiatria Clínica, 35, 61-64.

Krug, E. G. (2002). Relatório mundial sobre violência e saúde. Genebra: Organização Mundial de Saúde.

Martins, M. C., \& Pillon, S. C. (2008). A relação entre a iniciação do uso de drogas e o primeiro ato infracional entre os adolescentes em conflito com a lei. Cadernos de Saúde Pública, 24(5), 1112-1120.

Neiva-silva, L., Lisboa, C., \& Koller, S. (2005). Bioética na pesquisa com crianças e adolescentes em situação de risco: dilemas sobre o consentimento e a confidencialidade. DST - Jornal Brasileiro de Doenças Sexualmente Transmissíveis, 17(3), 201-206.

Oliveira, M. B., \& Assis, S. G. (1999). Os adolescentes infratores do Rio de Janeiro e as instituições que os "ressocializam". A perpetuação do descaso. Cadernos de Saúde Pública, 15(4), 831-844.

Polli, M. (2006). O sujeito na ciência: questões à bioética. Psicologia \& Sociedade, 18(3), 7-15.

Schramm, F., Palácios, M., \& Rego, S. (2008). O modelo bioético principialista para a análise da moralidade da pesquisa científica envolvendo seres humanos ainda é satisfatório? Ciência \& Saúde Coletiva, 13(2), 361-370.

Sena, C. A., \& Colares, V. (2008). Comportamentos de risco para a saúde entre adolescentes em conflito com a lei. Cadernos de Saúde Pública, 24(10), 2314-2322.

Vieira, S. (2005). Ética e metodologia na pesquisa médica. Revista Brasileira de Saúde Materno- Infantil, 5(2), 65-73.

Volpi, M. (1997). Adolescente e ato infracional. São Paulo: Cortez. 